\title{
PERBEDAAN KEJADIAN ALERGIPADA ANAK USIA 1TAHUN TERHADAP PEMBERIAN ASI EKSKLUSIF DI DESA BLUMBANGLAMONGAN
}

\author{
Silvi Ismala*, Firdaus** \\ (UNUSA, FIK, Prodi SI Keperawatan - Jl. Smea 57 Surabaya) \\ e-mail: firdausbakdil@yahoo.co.id
}

\begin{abstract}
This research is toto analyze the difference of allergy incidence happening to one-year-old children who are breastfed exclusively and those who are not in Blumbang Village, Lamongan. The design of study was analytic comparative-case control study. The population involved children aged one year old, totally 34 respondents. 31 respondents were chosen as the samples by using simple random sampling technique. The independent variable was the consumption of exclusive breast milk, whereas the dependent variable was the incidence of allergy. The data were collected by using questionnaires. The data were analyzed by using ChiSquare test and the significance level $\alpha=0.05$.the result of test showed that $p=0.031<$ $\alpha=0.05$ so that $\mathrm{H}_{0}$ was rejected describing that there was a difference of allergy incidence happening to one-year-old children who received exclusive breast milk and those who didn't receive breast milk from their mothers living in Blumbang Village, Lamongan.
\end{abstract}

Abstrak :Penelitian ini untuk menganalisisperbedaankejadianalergipadaanakusia 1tahunantarayang mendapatkan ASI eksklusifdan tidakmendapatkan ASI eksklusifdi desaBlumbang, Lamongan.Desainpenelitiananalitikkomparatif, mengunakanmetodecase control study.Populasipenelitianyaituanakusia 1 tahun sebesar 34 orang,sampelsebesar31respondendiambil dengantehniksimple random sampling. Variabel independen adalah mendapatkan ASI eksklusif dan tidak mendapatkan ASI eksklusif, variabel dependen adalah kejadian alergi. Pengumpulan data menggunakan kuesioner. Data dianalisismenggunakanujiChi Square dengantingkatkemaknaan 0,05.Hasilujididapatkan $\rho=0,031<\alpha=0,05$ maka $\mathrm{H}_{0}$ ditolakartinyaadaperbedaankejadianalergipadaanakusia 1tahun antarayang mendapatkan ASI eksklusifdan tidakmendapatkan ASI eksklusifBlumbang, Lamongan

Kata kunci :ASI eksklusif, tidakeksklusif, alergi, anak.

\section{PENDAHULUAN}

Beberapatahunterakhiriniadakecend erungankasusalergipadaanakmeningkat. Kasusalergi yang terjadipadaanakiniakanmenjadimasalah yang cukupdominan di masa yang akandatangkarenasebuahstudiInternasio nalmenunjukkanbahwa $25-50 \%$ anakmengalamialergi (Chairiniza, 2010). Kasusalergipadaanak inilahmerupakanhal yang akanmenjadiperhatian.

Permasalahanalergipadaanakmungkintid aksesederhanaseperti yang kitabayangkan.Seringberulangnyapenya kit, demikianluasnyasistemtubuh yang terganggukarenaalergi, sehinggadapatmenganggusemua organ danterjadibahayakomplikasitampaknya 
merupakanakibat

yang

haruslebihdiperhatikan

demi

terbentuknyapertumbuhandanperkemba

ngananak yang optimal.

Padaanakreaksialergi yang

terjadibermacam-macam. Anak yang menderitaalergiinikemungkinanbesar,

karenafaktorgenetik, faktorlingkungan,

dandefesiensisel

$\mathrm{T}$

akibattidakmendapatkan ASI eksklusif

(SamikWahab, 2002). ASI (Air SusuIbu) merupakanmakananuntukbayi yang

berasaldarikelenjarsusupadapayudaraibu

ASI

merupakansumbernutrisiterbaikuntukba

yi yang mengandungkolostrum yang terdapatimmunoglobulinAyang

bermanfaatuntukmeningkatkandayataha n

tubuhsehinggaanakmenjadikebaldandap atterhindardaripenyakitalergi (Purwanti, 2004).

Permasalahannya saat ini adalah banyak ibu yang tidak mau memberikan ASI eksklusif kepada anaknya dengan alasan ibu sibuk bekerja, ASI tidak cukup, dan bentuk payudara menjadi tidak indah lagi.

Menurut Dinas Kesehatan Propinsi Jawa Timur pada tahun 2008 jumlah bayi yang terlahir ada 719.332 bayi, dan yang diberi ASI eksklusif hanya sebesar $38,73 \%$ yang artinya ada $61,27 \%$ bayi yang lahir tidak mendapatkan ASI eksklusif(Dinkes Jatim, 2009). Data diatasmenunjukkansebesar $\quad 61,27 \%$ anakberesikoterkenaberbagaimacampen yakitsepertipenyakitalergi. Data awal yang

diperolehdaridesaBlumbang,Lamongan padabulanFebruari 2013terdapat 13anak usia 1 tahun yangmengalamialergi. Wawancara yang dilakukan kepada 5 ibu yang anaknya mengalami alergi, mengeluhkan anaknya gatal-gatal, timbul bintik atau bisul kemerahan atau penyuen, batuk pilek, muntah serta diare baik akibat alergi makanan dan alergi susu formula dan 5 anak yang mengalami alergi tidaksatupun yang mendapatkan ASI eksklusif.

Bayidananak-anakadalahmasa yang sangatsensitifkarenasaatitulahanakanakmulaitumbuhbaikfisikataupunment alnya.Banyak proses tumbuhkembangdalamtubuhanakpadaus ianyaitu. Apabila di masaanakusia 1tahunini,

seringmenderitapenyakitsepertialergiaka nberdampak pula pada proses tumbuhkembangnya yang akanterjadikarenaanak pun menjadireweldansulituntukmakansehing gaasupannutrisi yang masukberkurangdanpadaakhirnyaanakm engalamipertumbuhandanperkembanga $n$ yang tidak optimal.

Salah satu upaya anak mendapatkan ASI eksklusif secara maksimal dibutuhkan tugas dari tenaga kesehatan khususnya perawat untuk memberikan pendidikan kesehatan tentang pentingnya memberikan ASI eksklusif kepada ibu-ibu yang memiliki bayi di desa agar mau memberikan ASI eksklusif.

Berdasarkan uraian di atas dapat dirumuskan masalah :"Adakah perbedaan kejadian alergipada anak usia 1tahun antara yang mendapatkan ASI eksklusif dan tidak mendapatkan ASI eksklusif di desa Blumbang, Lamongan?". Tujuan umum untuk mengetahuiperbedaankejadianalergipad aanakusia 1tahun antarayang mendapatkan ASI eksklusifdan tidakmendapatkan ASI eksklusifdi desaBlumbang, Lamongan.

\section{METODE PENELITIAN}

Jenis dan rancang bangun dalam penelitian ini adalah penelitian yang bersifat analitik komparasi dengan menggunakan pendekatan case control 
Ismalai,Firdaus : Perbedaian alergi pada anak usia 1 tahun terhadap pemberian ASI eklslusif.19

study yaitu jenis studi yang berusahamelihatkebelakang.

Populasi dalam penelitian ini adalahanakusia 1 tahun di desaBlumbang,Lamongansebesar $\quad 34$ anak dan sampel yang digunakan dalam penelitian ini adalah sebagiananakusia 1 tahun sebesar 31 responden.

Teknik sampling yang digunakanadalahSimple Random Sampling

dilakukandenganpengambilansampelsec araacak dan memiliki kesempatan sama untuk dijadikan sampel.

Variabel dependen dalam penelitian ini adalah kejadian alergi dan variabel independen adalah mendapatkan ASI eksklusif dan tidak mendapatkan ASI eksklusif.Instrumen yang digunakan dalam penelitian ini adalah kuesioner yang diberikan pada ibu dari responden.

Cara pengumpulan data adalah penelitike rumah-rumah responden untuk meminta persetujuan, serta peneliti membagikan kuesioner. Data didapatkan dari ibu responden yang mengisi kuesioner tentang kejadian alergi yang dialami oleh responden dan tentang pemberian ASI eksklusif.

Data yang terkumpul akan dianalisis menggunakan SPSS 16.0 for windows dan dengan menggunakan uji statistik ChiSquaredengan tingkat kemaknaan $\alpha=0,05$. H0 ditolak jika $\rho<$ $\alpha$ yang berarti ada perbedaankejadianalergipadaanakusia 1tahunantarayang mendapatkan ASI eksklusifdan tidakmendapatkan ASI eksklusifdi desaBlumbang, Lamongan.

\section{HASIL PENELITIAN}

1. Data UmumResponden

Karakteristikrespondenberdasarkan umur ibu

Tabel1. Distribusi frekuensi umur ibu di desa Blumbang, Lamongan tahun 2013

\begin{tabular}{|c|c|c|}
\hline Umur & Frekuensi & $\begin{array}{l}\text { Persentase } \\
\quad(\%)\end{array}$ \\
\hline$<20$ tahun & 0 & 0,0 \\
\hline 20-35 tahun & 29 & 93,5 \\
\hline$>35$ tahun & 2 & 6,5 \\
\hline Jumlah & 31 & 100 \\
\hline $\begin{array}{l}\text { Karakteristik } \\
\text { pekerjaan }\end{array}$ & responden & berdasarkan \\
\hline \multicolumn{3}{|c|}{$\begin{array}{l}\text { frekuensipekerjaan ibu di desa } \\
\text { Blumbang, Lamongan tahun } 2013\end{array}$} \\
\hline Pekerjaan & Frekuensi & $\begin{array}{l}\text { Persentase } \\
(\%)\end{array}$ \\
\hline $\begin{array}{c}\text { Tidak } \\
\text { bekerja }\end{array}$ & 7 & 22,6 \\
\hline Bekerja & 24 & 77,4 \\
\hline Jumlah & 31 & 100 \\
\hline
\end{tabular}

2. Data khusus

Karakteristikkejadianalergipadarespond en

Tabel3.Distribusifrekuensikejadianal ergipadaresponden di desaBlumbang, Lamongantahun 2013

\begin{tabular}{lll}
\hline $\begin{array}{l}\text { Kejadian } \\
\text { Alergi }\end{array}$ & Frekuensi & $\begin{array}{l}\text { Persentase } \\
(\%)\end{array}$ \\
\hline Alergi (-) & 17 & 54,8 \\
Alergi (+) & 14 & 45,2 \\
\hline Jumlah & 31 & 100 \\
\hline
\end{tabular}

\section{Karakteristik penyebab alergi}

Tabel 4. Distribusi frekuensi penyebab alergi pada responden di desa Blumbang, Lamongan tahun 2013

\begin{tabular}{lll}
\hline $\begin{array}{l}\text { Penyebab } \\
\text { Alergi }\end{array}$ & $\begin{array}{l}\text { Frekuen } \\
\text { si }\end{array}$ & $\begin{array}{l}\text { Persentas } \\
\text { e }(\%)\end{array}$ \\
\hline $\begin{array}{l}\text { Susu } \\
\text { Formula(Hewa }\end{array}$ & 4 & 28,6 \\
ni) & & \\
Makanan & 8 & 57,1 \\
Bedak & 2 & 14,3 \\
\hline Jumlah & 14 & 100 \\
\hline
\end{tabular}

Karakteristikfaktor keturunan atau genetik 
Tabel5.Distribusifrekuensifaktor

20. Jurnal Ilmiah Kesehatan, Vol 7, No 12, Pebruari 2014., hal 17-22 hampir seluruh $(85,7 \%)$ responden tidak iI eksklusif.

I uji statistik ChiSquare

mengalamialergi di desaBlumbang,

Lamongantahun 2013

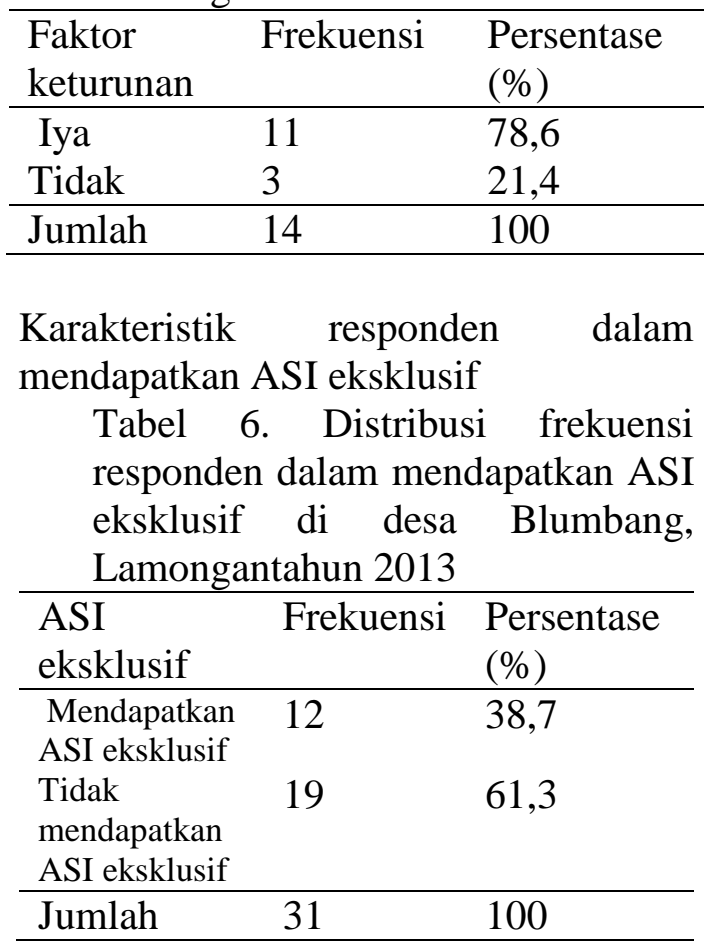

Perbedaankejadianalergipadaanakusia 1tahunantarayang mendapatkan ASI eksklusifdan tidakmendapatkan ASI eksklusifdi desaBlumbang, Lamongan

Tabel7.Distribusisilang perbedaankejadianalergipadaanakus ia 1tahunantarayang mendapatkan ASI eksklusifdan tidakmendapatkan ASI eksklusifdi desaBlumbang, Lamongan tahun 2013

\begin{tabular}{|c|c|c|c|}
\hline \multirow{5}{*}{$\begin{array}{l}\text { Kejadia } \\
n \text { alergi }\end{array}$} & \multicolumn{2}{|c|}{ ASI eksklusif } & \multirow{5}{*}{$\Sigma n(\%)$} \\
\hline & Mendapatka & \multirow{2}{*}{$\begin{array}{l}\text { Tidak } \\
\text { mendapatka }\end{array}$} & \\
\hline & $\mathrm{n} \quad \mathrm{ASI}$ & & \\
\hline & eksklusif & $\mathrm{n} \quad \mathrm{ASI}$ & \\
\hline & $\mathrm{n}(\%)$ & $\begin{array}{l}\text { eksklusif } \\
\mathrm{n}(\%)\end{array}$ & \\
\hline Alergi (- & $10(58,8)$ & $7(41,2)$ & $17(100$ \\
\hline Alergi & & & \\
\hline$(+)$ & $2(14,3)$ & $12(85,7)$ & (100) \\
\hline$\Sigma$ & $12(38,7)$ & $19(61,3)$ & 31 \\
\hline
\end{tabular}

Tabel 7. di atas menunjukkan bahwa dari 31 responden, terdapat 14 responden yangmengalami alergi, dengan menggunakan SPSS 16.0 for windows didapat $\rho=0,031<\alpha=0,05$ maka $\mathrm{H}_{0}$ ditolak artinya adaperbedaan kejadian alergipada anak usia 1tahun antara yang mendapatkan ASI eksklusif dan tidak mendapatkan ASI eksklusif di desa Blumbang, Lamongan serta diperoleh odds ratio $=8,5$ yang artinya resiko anak yang tidak mendapatkan ASI eksklusif adalah 8,5 kali mengalami alergi dibandingkan anak yang mendapatkan ASI eksklusif.

\section{PEMBAHASAN}

1. Kejadian alergi

Penelitianini akan menjelaskan tentang kejadian alergi yang dialami responden di desa Blumbang, Lamongan. Berdasarkan hasil penelitian di desa Blumbang, Lamongan ditemukan hampir setengah $(45,2 \%)$ responden mengalami alergi.

Kejadian alergi yang dialami responden di desa Blumbang banyak disebabkan oleh berbagai macam penyebab yaitu karena alergi makanan, susu formula (hewani) dan bedak. Reaksi yang dialami responden pun bermacam-macam, diantaranya responden mengalami gatal-gatal, diare, mual, muntah dan batuk pilek. Reaksi alergi yang dialami responden tersebut mengalami kekambuhan sebanyak 2 sampai 3 kali dalam sebulan. Rata-rata lama kejadian alergi yang dialami responden sekitar 3-7 hari. Hal ini didukung oleh teori Darmawan (2011) dikatakan alergi jika anak setelah terpapar oleh suatu benda yang kemudian menimbulkan reaksi pada anak tersebut misalkan makanan, debu, susu formula dan lain sebagainya dan anak akan mengalami kekambuhan 2 kali atau lebih dalam satu bulan. 
Menurut Samik wahab (2002)

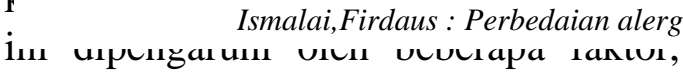
diantaranya faktor pajanan alergi atau penyebab alergi, faktor genetik. Hasil penelitian ini didapatkan sebagian besar $(57,1 \%)$ alergi yang dialami responden disebabkan karena makanan. Setiap individu memiliki kerentanan sensitivitas yang berbeda-beda, bagi anak yang memiliki sensitivitas tinggi terhadap makanan tertentu maka anak akan mengalami reaksi tertentu pula terhadap makanan tersebut, pada penelitian ini didapatkan dari penyebab alergi makanan di atas yang paling banyak adalah telur. Reaksi yang dialami responden berupa mual, muntah dan diare. Menurut teori Chairinniza (2010) menyatakan bahwa makanan merupakan salah satu penyebab munculnya kejadian alergi yaitu berdasarkan faktor alergen atau pemicu terjadinya alergi

Selain faktor tersebut, keturunan atau genetik merupakan salah satu faktor yang mempengaruhi kejadian alergi yang dialami responden, hal ini terbukti pada penelitian ini didapatkan hampir seluruh $(78,6 \%)$ responden dalam keluarga atau orang tua memiliki riwayat yang sama yaitu pernah mengalami alergi. Orang tua yang memiliki riwayat alergi ini biasanya akan menurunkan gen-gen alergi pada anaknya sehingga anak akan beresiko tinggi menderita alergi atau biasanya disebut membawa sifat dari orang tua. Hal ini sesuai dengan teori Samikwahab, (2002) bahwa alergidapatditurunkandari orang tua, kakek, dan nenekpenderita. Bilaada orang tua, kakek dan nenek yang menderitaalergiharus

lebihmewaspadaitandaalergipadaanakse jakdini.Penelitiannya menunjukkanbahwa orang tua yang menderitaalergicenderungmempunyaian akmenderitaalergilebihdari

$\cdots$.

ak usia 1 tahun terhadap pemberian ASI eklslusif.21

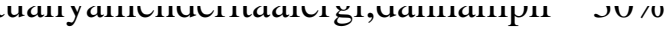
jikahanyasalahsatu orang tuanyayang menderitaalergi.

2. ASI eksklusif

Berdasarkan hasil penelitian di desa Blumbang, Lamongan didapatkan sebagian besar $(61,3 \%)$ responden tidak mendapatkan ASI eksklusif.

Menurut Suparyanto (2011)banyak faktor yang mempengaruhi pemberian ASI eksklusif ini, diantaranya yaitu dipengaruhi faktor internal yaitu oleh umur serta faktor eksternal yaitu pekerjaan. Berdasarkan hasil penelitian ini didapatkan bahwa hampir seluruh $(93,5 \%)$ ibu berumur 20-35tahun. Umur 20-35 tahun ini tergolong dalam umur produktif. Menurut Mubarak (2010) semakin bertambahnya umur seseorang akan terjadi perubahan aspek fisik dan psikologis yang menyebabkan taraf berfikir seseorang semakin matang dan dewasa. Meskipun hampir seluruh ibu tergolong usia produktif akan tetapi di desa Blumbang belum pernah diadakan penyuluhan tentang pentingnya pemberian ASI eksklusif, ibu pun sulit menerima informasi jika belum pernah diadakan penyuluhan oleh petugas kesehatan.

Selain faktor tersebut, faktor yang mempengaruhi pemberian ASI eksklusif yaitu pekerjaan di mana banyak ibu mengatakan bahwa ibu sibuk bekerja dan tidak sempat memberikan ASI eksklusif pada anaknya. Penelitian ini didapatkan bahwa hampir seluruh(77,4\%) ibu adalah bekerja. Pekerjaan yang dilakukan ibu di desa Blumbang ini kebanyakan sebagai pedagang di luar rumah dan guru yang mana ibu yang bekerja ini lebih banyak menghabiskan waktunya di tempat kerja dan tidak memiliki cukup waktu untuk memberikan ASI eksklusif. Hal ini sesuai dengan teori Supartini (2004) 
menyatakan bahwa tuntutan pekerjaan

y 22. Jurnal Ilmiah Kesehatan, Vol 7, No 12, Pebruari 2014., hal 17-22

$\mathrm{p}$

3. Perbedaan kejadian alergı antara yang mendapatkan ASI eksklusif dan tidak mendapatkan ASI eksklusif.

Apabila ASI eksklusif tidak diberikan kepada responden maka resiko responden mengalami alergi semakin tinggi, hal ini terbukti hasil penelitian di desa Blumbang diperoleh dari responden yang mengalami alergi hampir seluruh $(85,7 \%)$ responden tidak mendapatkan ASI eksklusif, serta dari responden yang tidak mengalami alergi hampir sebagian besar $(58,8 \%)$ responden mendapatkan ASI eksklusif. ASI eksklusif sangat penting untuk anak karena ASI eksklusif bermanfaat untuk meningkatkan kekebalan tubuh, sehingga anak yang mendapatkan ASI eksklusif menjadi kebal dan tidak mudah sakit. Semakin banyak anak yang tidak mendapatkan ASI eksklusif maka semakin banyak pula resiko anak yang mengalami alergi karena kekebalan tubuhnya yang kurang baik. Hal ini sesuai dengan teori Sri purwanti (2004) menyatakan peranan ASI eksklusif terhadap alergi karena ASI mengandung alfa tokoferol, sistin, dan vitamin $\mathrm{C}$ yang berfungsi menghalau oksigen radikal bebas juga sebagai antioksidan, histaminase untuk mencegah degradasi histamin, serta terdapat immunoglobulinAyang bermanfaat untuk meningkatkan daya tahan tubuh sehingga anak menjadi kebal dan dapat terhindar dari penyakit alergi.

\section{SIMPULAN}

1. Anak di desa Blumbang, Lamongan hampir setengah mengalami alergi.

2. Anak di desa Blumbang, Lamongan hampir setengah yang mendapatkan ASI eksklusif dan sar tidak mendapatkan if.

3. Adaperbedaankejadianalergipadaan akusia 1tahunantarayang mendapatkanASI eksklusifdan tidakmendapatkan ASI eksklusifdi desaBlumbang, Lamongan

\section{DAFTAR RUJUKAN}

Darmawan.

2011.

Seringnyapenyakitalergi.

htp://www.kompas.com

tanggalakses 21 Feb 2013.

Dinkes. 2009. Rendahnyapemberian ASI

eksklusif.http://www.dinkesjatim. go.id html/ tanggal akses $25 \mathrm{Nov}$ 2012.

Graha, Chirinniza. 2010. 100 Questions \&answers alergi pada anak. Jakarta : Media komputindo.

Mubarak, WahitIqbal. 2011. Promosikesehatanuntukkebidanan . Jakarta :SalembaMedika.

Notoatmodjo, Soekidjo. 2012. Promosi kesehatandanilmuperilakukesehat an. Jakarta : Rineka Cipta.

Prastyono, Sunar. 2009. Buku pintar ASI eksklusif pengenalan, praktik, dan kemanfaat-kemanfaatanya . Yogyakarta :Diva Press.

Purwanti. 2004. Konsep penerapan ASI eksklusif : buku saku bidan. Jakarta : EGC.

Supartini, $\quad$ Yupi. 2004. Bukuajarkonsepdasarkeperawata nanak. Jakarta : EGC.

Wahab, A. Samik. 2002. Sistemimun, imunisasi, danpenyakitimun. Jakarta :WidyaMedika. 
